\title{
Thermo-Mechanical and Thermal Properties of Binary Particle Nanocomposite Exposed to Sea Water Conditioning
}

\author{
Tcherbi-Narteh A*, Mohammed Z, Hosur M and \\ J eelani S \\ Department of Materials Science Engineering, Tuskegee \\ University, USA \\ *Correspondling author: Tcherbi-Narteh A, \\ Department of Materials Science Engineering, 127 \\ Chappie J ames Center, Tuskegee University, Tuskegee, \\ Alabama 36088, USA
}

Received: May 04, 2018; Accepted: J une 05, 2018; Published: J une 12, 2018

\begin{abstract}
Objective of this study was to explore binary nanoparticles consisting of Montmorillonite nanoclay Nanomer ${ }^{\circledR}$ I.30E (MMT) and amine functionalized Graphene Nanoplatelets (GNP) as reinforcements in epoxy SC780 composite to minimize seawater absorption and its impact on material properties. Composite samples fabricated were 2 and 3 wt $\%$ MMT; 0.1 and 0.2 wt \% GNP and binary nanocomposites consisting of 3 wt \% MMT/0.1 wt \% GNP and conditioned by complete immersion into seawater at room temperature for 240 days. Viscoelastic and thermal properties were characterized prior to and post conditioning using Dynamic Mechanical Analysis (DMA), Thermo-Mechanical Analysis (TMA) and Thermogravimetric Analysis (TGA) respectively. Binary nanocomposites absorbed the least amount of seawater, while $3 \mathrm{wt} \%$ MMT and $0.2 \mathrm{wt} \%$ GNP absorbed the most. Storage modulus of unconditioned binary nanocomposite increased by nearly $29 \%$ compared to neat; however, it showed the highest reduction after conditioning among all samples including neat. Binary samples also showed better dimensional stability at elevated temperatures prior to and post conditioning when compared to all samples. Nanocomposites showed relatively lower glass transition temperatures compared to neat samples.
\end{abstract}

Keywords: Thermo-mechanical; Binary nanoparticles; Seawater absorption; Nanocomposites

\section{Introduction}

Application of nanoparticles to enhance properties of polymeric composite materials have been widely studied leading to the development of advanced polymer materials with enhanced properties [1-3]. Enhanced barrier and viscoelastic properties of polymer composites are particularly of great importance to marine applications, where most structures are exposed to prolong seawater conditioning. Other targeted properties of polymer include enhanced durability through minimization or delayed detrimental effects of service and environmental factors over time [4,5]. Increasing demand for advanced composite materials across different industries has given rise to the development of next generation state of the art advanced materials systems with multi-functionality. Development of polymer composite systems with multi-functional capabilities requires a thorough understanding of material systems including the use of multiple nanofillers. In recent years binary or hybrid nanoparticles systems have been gaining research attention, where two characteristically different nanoparticles are dispersed together in polymer systems to enhance various material properties [6-8]. Thus, desirable properties of each nanoparticle are targeted and harnessed through their interactions with each other and host polymer resulting in composites with multi-functionality.

Research in this area is however new and requires careful selections of materials with complete understanding of interphase and interfacial chemistry of nanoparticles and appropriate polymer $[9,10]$. Additionally, the role of individual and combined nanoparticles on chemico-physical and chemico-rheological properties of the polymer is of significant importance. This leads to the development of customized parameters necessary for processing such combination and ultimate curing of the final composite [11,12]. Generally, enhanced properties of polymers by nanoparticles have been attributed to structural morphologies, degree of dispersion throughout the polymer, and interfacial interaction between nanoparticles and host polymers and degree of cure $[12,13]$. Degree of cure in polymers has been influenced by the type and concentration of nanoparticles present in the polymeric systems [14].

Targeted properties of most materials used in marine and outdoor applications include ability to resist corrosion, minimize moisture absorption and withstand impact of other environmental factors. Polymer composites display such characteristics and hence widely used in marine industries including painting and coating. However, there is a major drawback associated with polymers, thus they are sensitive to temperature, certain basic and acidic solution conditions, and are prone to moisture absorption due to their viscoelastic nature [15].

Numerous studies have been conducted on durability of polymeric composites exposed to different environments using different nanoparticles. These include exposure to UV radiation, extreme temperatures, moisture, alkaline solution, and other fluids $[4,5,16]$. Moisture aging induces physico-chemical changes in polymer composites, which tend to degrade the material properties over time [16]. These changes include swelling of the matrix by 
hydrolysis affecting dimensional stability and plasticization, which deteriorates interfacial bonding between fibers and the matrix in Fiber Reinforced Polymer Composite (FRPC), affecting both the mechanical and thermo-mechanical properties $[15,16]$. Abanilla et al. [17] Studied the effects of alkali solution, freeze-thaw and accelerated aqueous exposure on graphite/epoxy composite and concluded that the strength of the matrix and overall composite degraded mostly due to moisture absorption. They also reported no significant change in the modulus of the composite. Zainuddin et al., [5] reported reduced degradation activities in strength and modulus of the composite samples reinforced with nanoclay and subjected to hot and cold environments. Tcherbi-Narteh et al., studied the effects of UV radiation and associated temperatures on properties of polymer nanocomposites materials $[4,12]$. The use of nanoparticles as reinforcement in polymer composites has shown significant progress in mitigating some of the impacts from environmental elements.

Graphene nanoplatelets and montmorillonite nanoclays are both two-dimensional nanoplatelets with dimensions commonly used as nano-reinforcements in polymeric composites. In recent years, both have attracted significant attention due to relatively low cost and remarkable enhancements in polymeric composites [13]. Morphologies of MMT and GNP infused polymer composite material exhibit similar states and their targeted properties depend on processing, concentration, chemical compatibility and distribution within the host matrix. Modulus and intrinsic strength of GNP are $1 \mathrm{TPa}$ and $130 \mathrm{GPa}$ respectively, 50 times stronger than steel, with surface area twice as Carbon Nanotubes (CNT) [13]. MMT also displays similar aspect ratios to that of graphene-based filler materials; however, MMT has higher density compared to GNP. In recent years, properties of polymer matrix used in FRPC materials have been modified continually to offset some of these environmental challenges using variety of systems. Significant amount of information has been acquired through studies regarding rates and absorption mechanisms based on the type of reinforcements, polymers and exposed medium [18]. In the current study, two high aspect ratio nanoparticles GNP and MMT with distinct characteristic were used as reinforcements individually and as binary reinforcements to enhance properties of SC-780 epoxy composites. Epoxy samples were fabricated using individual nanoparticles and binary consisting of 3 wt \% MMT/0.1 wt \% GNP (MMT/GNP) respectively. Fabricated samples were conditioned in seawater for 240 days and various properties characterized. Mechanical and thermal properties were characterized using three-point bending flexure tests, Dynamic Mechanical Analyses (DMA) and Thermo-Mechanical Analysis (TMA). Properties of binary systems were compared to those of unmodified and modified epoxy composites loaded with individual nanoparticles.

\section{Experimentation}

\section{Materials}

A two-part diglycidyl ether of bisphenol A based epoxy, SC-780 consisting of Part A (resin) and part B (curing agent or hardener) from Applied Poleramics Inc. and used in the study. Mixing ratio of the epoxy resin part A and part B is 100:22 by mass. Two different nanoparticle reinforcements used in the study. Graphene Nanoplatelets (GNP) was obtained from ACS Materials LLC, (USA)

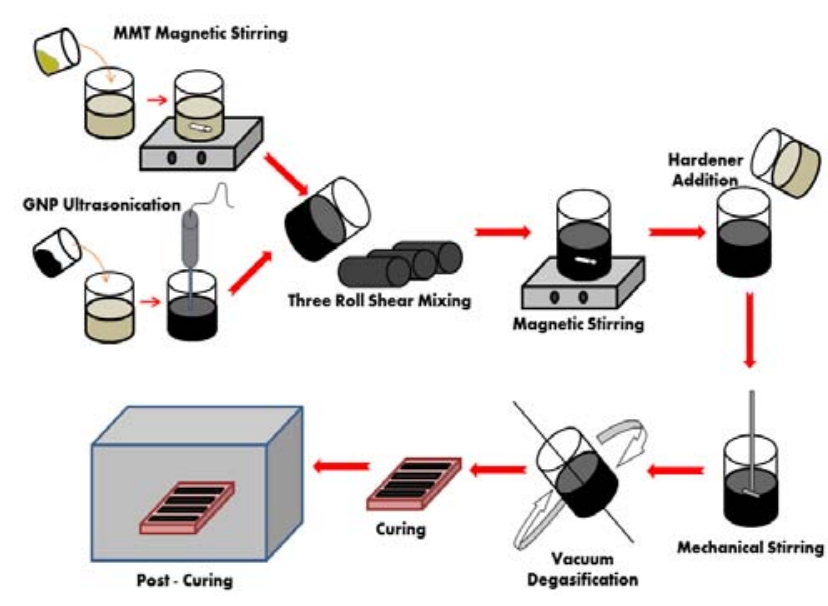

Figure 1: Summary of nanocomposite fabrication process.

with particle thickness between 2-10 nm, and Montmorillonite Nanoclay (MMT) was purchased from Sigma Aldrich. Surface of MMT has been modified with 20 - 35 wt \% octadeclyamine with average particle size of $10-12 \mathrm{~nm}$ and sold under the trade name Nanomer I.30E.

\section{Fabrication of epoxy nanocomposite}

Fabrication of unmodified and modified epoxy composites using different loadings of various nanoparticles was done by first dispersing these nanoparticles into part A of epoxy resin. Samples fabricated were 0.1 and $0.2 \mathrm{wt} \% \mathrm{GNP}, 2$ and $3 \mathrm{wt} \% \mathrm{MMT}$ and MMT/ GNP epoxy nanocomposite samples. Measured amount of MMT was dried in a vacuum oven at temperature $50^{\circ} \mathrm{C}$ for two hours, due to hydrophilic nature of organoclay. MMT/SC780 was magnetically stirred at $400 \mathrm{rpm}$ for 24 hours at room temperature. Calculated amount of GNP was mixed in the epoxy resin, stirred manually followed by ultrasonication for 1 hour. Sonication parameters used were pulse rate of $20 \mathrm{sec}$ on and $30 \mathrm{secs}$ off using $45 \%$ amplitude, while maintaining the mixture in a cooling bath set at $40^{\circ} \mathrm{C}$ for both GNP and $h \mathrm{BN}$ samples respectively. Sonicated mixture of GNP/SC-780 was magnetically stirred to further disperse for about six hours at $400 \mathrm{rpm}$. GNP/SC780 mixture was further processed using three-roll shear mixer with gap between the rollers set at 15,10 and $5 \mu \mathrm{m}$ with speed of rollers at $120 \mathrm{rpm}$ for three passes. For binary nanocomposite fabrications, measured amount of resin was divided into two unequal parts in beakers. Calculated amount of dried nanoclay was mixed and magnetically stirred in the larger portion for 15 hours, while determined amount of GNP nanoparticles were dispersed in the other part of resin part A and sonicated at the same conditions discussed earlier. Sonicated GNP/resin mixture was added to nanoclay mixed resin solution and combined mixture was subsequently processed through three-roll shear mixer using parameters discussed earlier followed by magnetic stirring for six hours. SC-780-part B was added to each nanoparticle dispersed part A, mechanically stirred and degasified using "Thinky" vacuum mixer for 15 minutes, at $30 \mathrm{kPa}$ pressure and $1500 \mathrm{rpm}$. Figure 1 shows summary of the fabrication of unmodified and modified epoxy nanocomposites.

\section{Marine conditioning}

Fabricated epoxy composite samples were conditioned by 


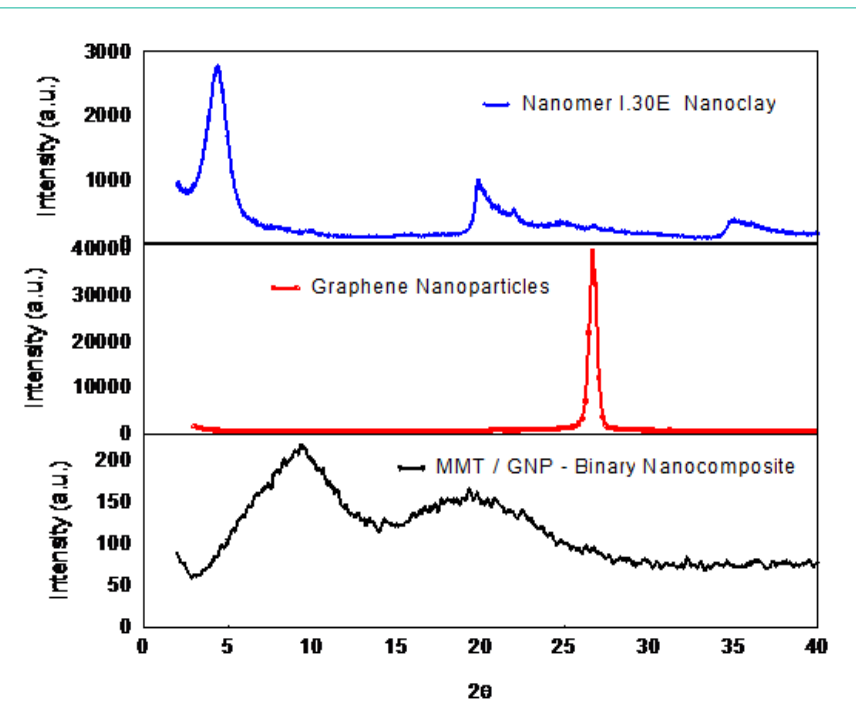

Figure 2: XRD diffraction of GNP, MMT and combined GNP/MMT Nanocomposite.

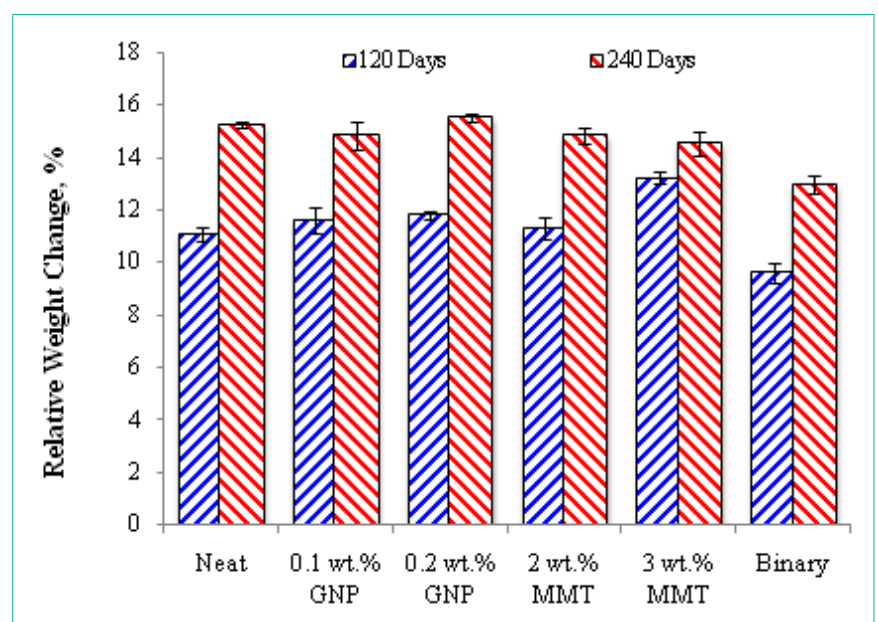

Figure 3: Percent relative seawater absorbed by samples at 120 and 240 days conditioning.

complete submersion into industrial grade seawater at room temperature. Representative samples were identified and their respective weight recorded prior to and during conditioning. Samples are removed every 120 days, patted with dry paper towel to remove dripping seawater, weighed and placed back into the conditioning container. Samples were conditioned for 240 days and various properties characterized, to study the effects of conditioning on each sample. Weight gained by each sample was used to characterize rate of deterioration in composite material properties based on absorbed seawater.

\section{Characterization}

\section{Microstructural analysis}

Analysis of dispersion state of each individual and binary nanoparticle systems on microstructural changes in SC780 epoxy matrix composites was studied using X-Ray Diffraction (XRD) technique. Rigaku DMAX 2000 with $\mathrm{Cu}$ Ka radiation of wavelength $\lambda=1.54 \mathrm{~nm}$ was used and operated at $40 \mathrm{kV}$ and $30 \mathrm{~A}$. Powdered nanoparticle samples and their respective epoxy nanocomposites samples were prepared, XRD scan counts were accumulated every $0.01^{\circ}(2 \theta)$ from 2 to $50^{\circ}$ at a scan rate of $0.2^{\circ} / \mathrm{min}$. XRD profile peaks from each pristine nanoparticle were compared to those obtained from their respective nanocomposites, to establish degree of disorderliness using Bragg's law $(\mathrm{n} \lambda=2 \mathrm{~d} \sin \theta)$.

\section{Dynamic mechanical analysis}

Viscoelastic properties of SC780 composites infused with various nanoparticles including binary considered were investigated using Dynamic Mechanical Analysis (DMA). The study was done using TA Instruments' Q800 operated in dual cantilever mode according to ASTM 6065. Samples were tested from 30 to $160^{\circ} \mathrm{C}$ at amplitude of $15 \mu \mathrm{m}$ and frequency of $1 \mathrm{~Hz}$. Characteristic storage and loss moduli, and tan delta curves were obtained as function of temperature for each sample. Three samples from each set were tested and average glass transition temperature $(\mathrm{Tg})$ determined from peak of loss modulus curve were obtained for comparison.

\section{Thermo-Mechanical Analysis (TMA)}

Dimensional stability of unconditioned and conditioned epoxy SC780 composites was studied using Thermo-Mechanical Analysis (TMA). TA Instruments' Q-400 equipped with expansion probe was used and three samples from each set was scanned at $5^{\circ} \mathrm{C} / \mathrm{min}$ from 30 $-150^{\circ} \mathrm{C}$. The equipment was purged with dry nitrogen at a flow rate of $50 \mathrm{~mL} / \mathrm{min}$. Coefficients of thermal expansion before glass transition $\left(\alpha_{1}\right)$ and after glass transition $\left(\alpha_{2}\right)$ were determined from each sample set according to ASTM D676 standards. Three samples were selected from each set and average data compared.

\section{Thermogravimetric Analysis (TGA)}

Influence of individual nanoparticles and binary on thermal stability of unconditioned and conditioned epoxy SC780 composites was studied using TA Instruments' Thermo-Gravimetric Analysis (TGA), Q-500. The instrument was purged with dry nitrogen gas at flow rate of 90 and $10 \mathrm{~mL} / \mathrm{min}$ for furnace and sample respectively. Three samples were prepared from each sample batch with weights between 13 and $15 \mathrm{mg}$ and scanned at $10^{\circ} \mathrm{C} / \mathrm{min}$ from $30-600^{\circ} \mathrm{C}$. Onset of Thermal decomposition $\left(\mathrm{T}_{5}\right)$, decomposition Temperature $\left(\mathrm{T}_{\mathrm{p}}\right)$ and residue parameters were determined for each scan and average data compared.

\section{Results and Discussion}

\section{Microstructural characterization}

Quantitative analyses of dispersion of nanoparticles including binary in epoxy SC780 composites were studied using X-Ray Diffraction (XRD) technique. Figure 2 shows representative XRD patterns obtained from GNP, MMT and MMT/GNP binary nanocomposites for quantitative analyses. Characteristic peaks of MMT powder were observed at around $2 \theta$ values of $4.85^{\circ}, 21.5^{\circ}$ and $37.2^{\circ}$ with varying intensities. Peak at $2 \theta=4.85^{\circ}$ is indicative of the highly arranged layers of clay platelets with intensity of around 2800 counts. Similarly, characteristic peak of graphene nanoplatelets were also observed at $2 \theta$ value of $26.85^{\circ}$ with corresponding intensity of approximately 40,000 counts. Morphological studies of binary nanocomposite of the two nanoparticles showed broader peaks with significantly lower intensities. Data from the studies indicate increased intergallery spacing of individual nanoparticles in their 


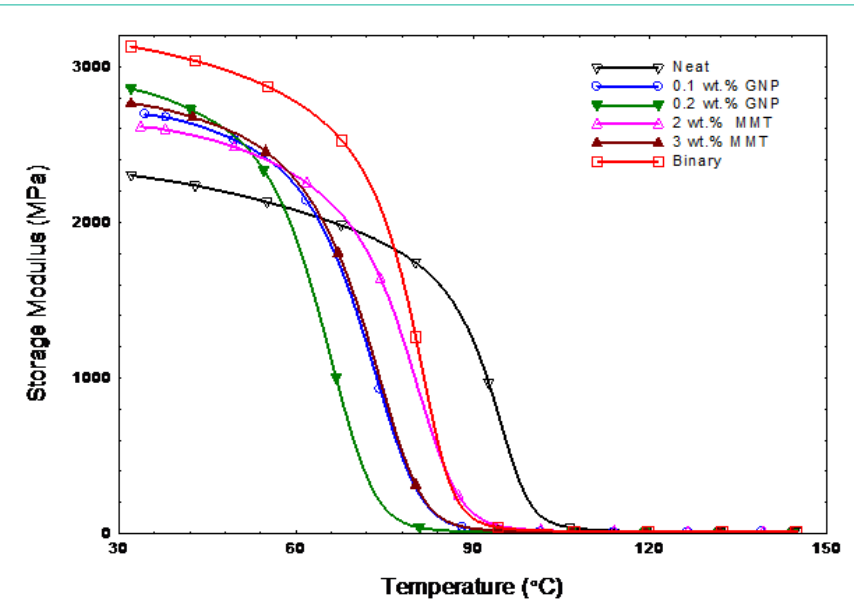

Figure 4: Representative storage moduli curves of unconditioned samples.

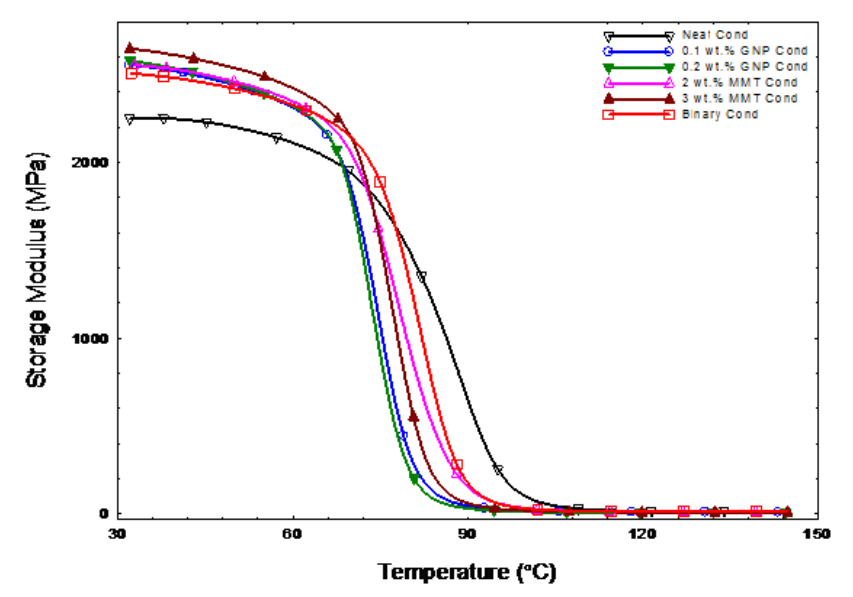

Figure 5: Representative storage moduli curves of conditioned samples.

respective nanocomposites. Thus, there was reasonable interaction between these nanoparticles and SC-780 epoxy molecules to cause the opening of the nanoplatelets morphology.

\section{Seawater absorption characteristics}

Initial weights of identified samples were measured and recorded, and changes in weights monitored with respect to initial weights of each selected samples after 120 days and 240 days. Summary of recorded weight changes are presented in (Figure 3), depicting average relative weight gained by each sample including neat. The results after 120 days indicate an initial spike in seawater absorption by nanocomposites compared to unmodified system. This may be attributed to interfacial distributions between nanoparticles and polymer chains, allowing for the movement of seawater molecules to penetrate between the polymer chains [19]. Samples with $3 \mathrm{wt}$ $\%$ MMT absorbed the most seawater followed by $0.2 \mathrm{wt} \% \mathrm{GNP}$ at the end of 120 days. High seawater content in 3 wt \% MMT samples was attributed to hydrophilic nature of MMT, while existence of high van der Waal forces in GNP may have contributed to increased chain length and distribution in the formation of highly cross-linked system [13]. Bridging effects of high aspect ratio nanoparticles can result in the formation of longer chain lengths, lowering the resistance to mobility and confinements of chains to form oligomers [20]. Hence, at relatively high percentage loading of GNP nanoparticles, there is an increased tendency for agglomeration and formation of inhomogeneous system. This can lead to increased moisture absorption in such polymer materials, accounting for the relative increase in $0.2 \mathrm{wt} \%$ GNP compared to $0.1 \mathrm{wt} \%$ GNP samples. Binary nanocomposites on the other hand absorbed the least amount of seawater among all nanocomposite samples including neat over the same duration. Nanoparticles in this system complimented each other resulting in enhanced barrier properties. Similar findings were observed at the end of 240 days of conditioning and reported in (Figure 3).

\section{Viscoelastic characterization}

Representative storage moduli thermographs obtained from DMA scans of unconditioned and conditioned samples are presented in Figures 4 and 5 respectively. Results of the scans showed overall increase in storage moduli and a decrease in glass transition temperatures of all nano infused samples to varying degrees. Enhancements in storage moduli were attributed to interactions between these nanoparticles and epoxy molecules resulting in entrapments of polymer chains within the filler network, resisting polymer chain movements $[10,20]$. Furthermore, these enhancements are also dictated by the concentration and inherent properties of individual nanoparticles, resulting disproportionate degrees among different set of samples. Storage modulus determined at $30^{\circ} \mathrm{C}$ showed an increase of approximately 15 and $21 \%$ for 0.1 and $0.2 \mathrm{wt} \%$ GNP loadings.

Similarly, an increase of approximately 12 and $17 \%$ was observed in 2 and 3 wt \% MMT samples respectively. This is indicative of prevailing interlocking strength between reinforcing nanoparticles and polymer molecules under cyclic loading $[9,20]$. Furthermore, presence of amine functional groups on GNP nanoparticles facilitates formation of strong covalent bonds in their polymeric structures. This was observed in $0.2 \mathrm{wt} \%$ GNP samples improving storage modulus of SC780 epoxy composites by nearly $21 \%$ [13]. Binary nanocomposites showed the highest overall increase in storage modulus of epoxy SC-780 by approximately $29 \%$ compared to neat samples. The enhancement was attributed to the synergy between the nanoparticles and epoxy molecules, increasing bridging effect and enhancing polymer chain network formation and crosslinking [21]. Thus, increased crosslinking in polymers reduces the amorphous regions of the polymer system, resulting in decreased glass transition temperatures as can be seen from (Table 1) [10]. The results also highlight the effectiveness of individual nanoparticles to bridge more polymer chains to form crystalline regions within the polymeric system. Glass transition temperature decreased across the board with $0.2 \mathrm{wt} \%$ GNP displaying the lowest values compared to neat. Despite binary nanocomposite system showing the highest enhancements in storage modulus, their glass transition temperature decreased by nearly $14 \%$ compared to that of neat. Samples with $0.1 \mathrm{wt} \%$ loading of GNP and 3 wt \% loading of MMT showed similar degree of enhancements in viscoelastic properties, despite significant difference in percent loading of each nanoparticle. Inherent properties of individual nanoparticles discussed earlier played key role in their interactions with epoxy polymer molecules leading to varying degree of enhancements. 
Table 1: Comparison of average viscoelastic properties of neat and nanocomposites samples.

\begin{tabular}{|c|c|c|c|}
\hline Sample & $\begin{array}{c}\text { Storage Modulus } \\
(\mathrm{MPa})\end{array}$ & $\begin{array}{c}\% \\
\text { Change }\end{array}$ & $\begin{array}{c}\% \\
\text { Change }\end{array}$ \\
\hline Neat & $2329.33 \pm 13.44$ & - & $103.51 \pm 1.18$ \\
\hline 0.1 wt. \% GNP & $2675.66 \pm 50.15$ & 14.86 & $85.90 \pm 0.75$ \\
\hline 0.2 wt. \% GNP & $2817.67 \pm 92.29$ & 20.96 & $79.83 \pm 0.49$ \\
\hline 2 wt. \% MMT & $2607.56 \pm 51.32$ & 11.94 & $93.67 \pm 1.92$ \\
\hline 3 wt. \% MMT & $2725.00 \pm 53.28$ & 16.99 & $84.75 \pm 1.23$ \\
\hline Binary & $2995.67 \pm 88.39$ & 28.57 & -10.50 \\
\hline
\end{tabular}

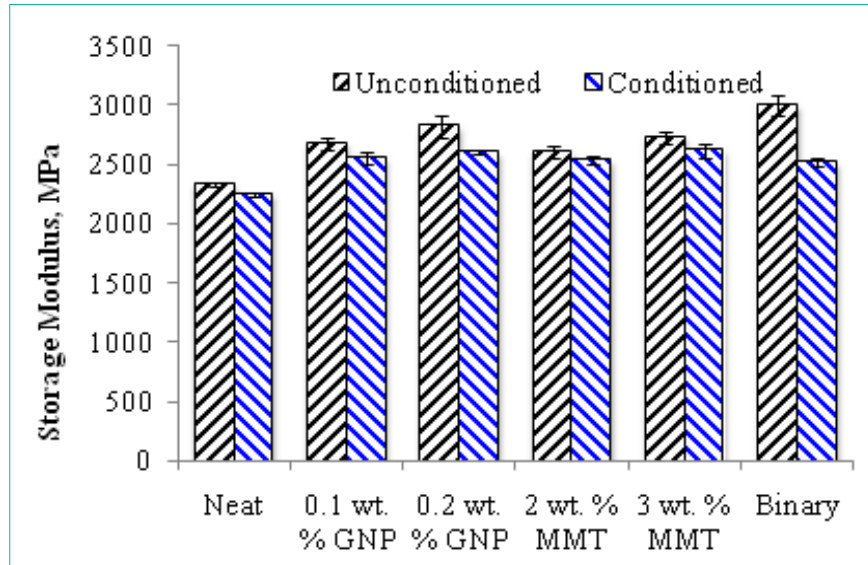

Figure 6: Comparison of storage moduli of unconditioned and conditioned samples.

Figure 5 shows representative storage moduli curves of samples conditioned after 240 days and comparison of average data between conditioned and unconditioned presented in (Figures 6,7). Moisture absorbed by polymeric composites and associated moisture induced stresses causes materials to experience dilatational expansion, affecting their overall properties, durability and structural integrity $[15,19]$. Viscoelastic properties of SC780 composites decreased across the board in all conditioned samples compared to their respective unconditioned counterpart due to plasticizing effect of water molecules [19]. However, DMA results from conditioned samples showed similar trend observed in unconditioned storage moduli enhancements in nanocomposite with respect to neat. Samples with 2 wt \% MMT loading showed the least reduction in storage modulus with respect to its unconditioned counterpart, a decrease of approximately $3 \%$, while binary showed the largest, $16 \%$ decreased of the same. Interactions between individual nanoparticles, epoxy and water molecules can result in different absorption kinetics at the interfacial level [16]. Here, the cumulative effect resulted in deterioration in material properties compared to unconditioned counterpart as shown in (Figure 6).

On the other hand, glass transition temperature decreased by nearly $5 \%$ in neat samples, while an increase was observed in all nanocomposite up to $6 \%$ in $0.2 \mathrm{wt} \%$ GNP samples, and statistically unchanged in $0.1 \mathrm{wt} \% \mathrm{GNP}$ and $2 \mathrm{wt} \%$ MMT samples. The increase in Tg was attributed to structural changes caused by absorbed moisture $[10,16]$. Samples with 3 wt \% MMT loadings showed the highest storage modulus values among all samples followed by 0.2 wt \% GNP samples, despite the latter absorbing the most seawater at the end of the conditioning. Relative increase in storage modulus

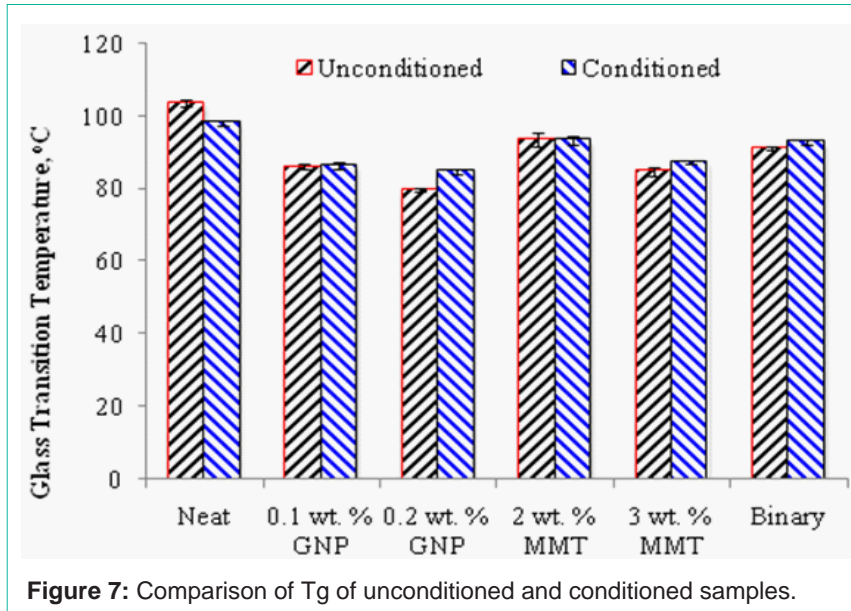

of these two samples constitutes approximately $16 \%$ with respective to neat counterpart. Post conditioned binary nanocomposites showed the least enhancement in storage modulus values among all nanocomposites, and approximately $12 \%$ improvements compared to neat samples, despite absorbing the least amount of seawater during conditioning. Binary nanocomposite lost the most in storage modulus, while 2 wt $\%$ MMT samples lost the least among all samples between unconditioned and conditioned. Ability of nanoparticles to retain desired viscoelastic properties after seawater conditioning underscores its effectiveness in preventing moisture ingress and minimization of such effect [9].

\section{Thermomechanical characterization}

Figure 8a shows representative TMA curves from scan obtained from each set of samples prior to conditioning, depicting dimensional stability as function of temperature. Values of CTE before glass transition $\left(\alpha_{1}\right)$ and after transition $\left(\alpha_{2}\right)$ were determined from slopes of the curves in each scan and results summarized in (Table 2 ). The results show a slight increase in $\alpha_{1}$ values for all nanocomposites with respect to neat, except binary which showed no statistical difference as shown in (Table 2). On the other hand, $\alpha_{2}$ values for all nanocomposites were lower than that of neat samples. These observations were attributed to the presence and inherent properties of different nanoparticles bridging the polymer chains and consequently resulting in higher degree of crosslink density compared to neat samples [20]. Relatively low values of $\alpha_{1}$ observed in $0.1 \mathrm{wt} \% \mathrm{GNP}$ were attributed to increased reactivity and presence of amine functional groups resulting in highly cross-linked chains, leading to a more thermally stable material [1]. The opposite was observed in 3 wt \% MMT samples where initial heating resulted in delayed crosslinking and hence higher CTE values of $\alpha_{1}$ prior to glass transition. Interactions between nanoparticles in 


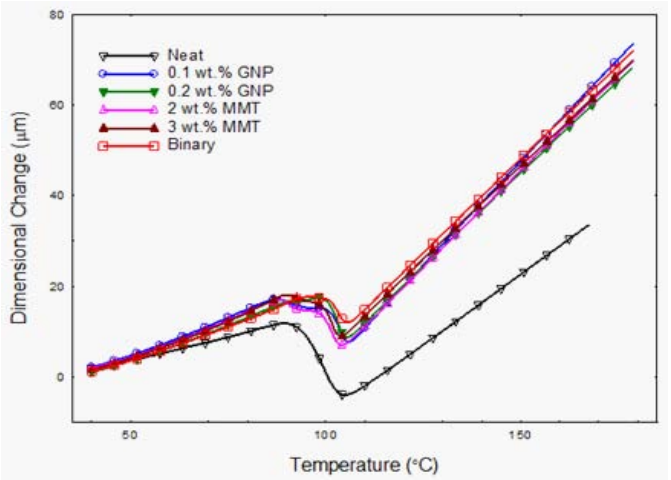

(a)

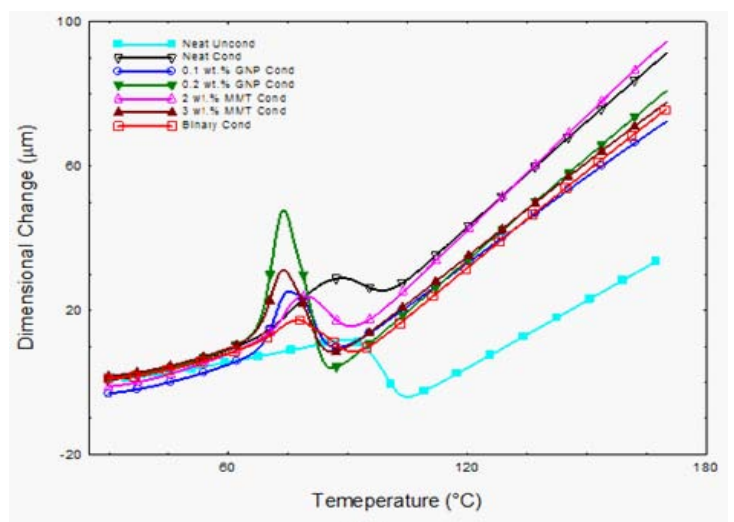

(b)

Figure 8: Representative TMA Curves for (a) Unconditioned and (b) Conditioned Neat and Various Nanocomposites.

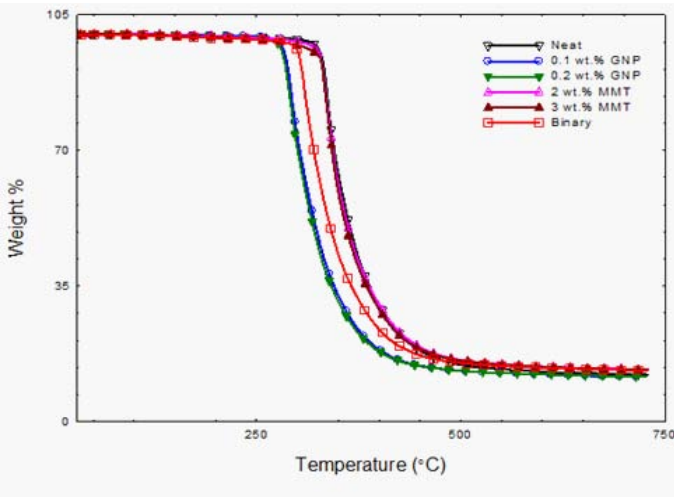

(a)

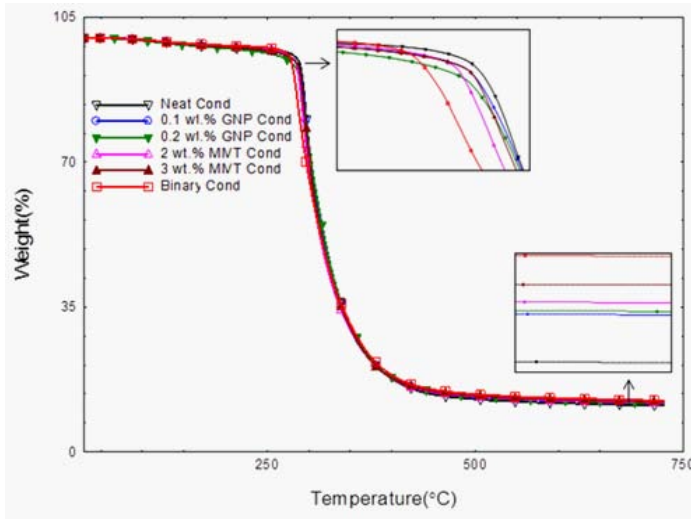

(b)

Figure 9: Representative TGA weight loss curve versus temperature for (a) unconditioned and (b) conditioned samples.

Table 2: Comparison of CTE values of unconditioned neat and nanocomposites samples.

\begin{tabular}{|c|c|c|c|c|}
\hline Sample & $\mathrm{CTE}\left(\alpha_{1}\right), \mu \mathrm{m} / \mathrm{m} \cdot{ }^{\circ} \mathrm{C}$ & $\%$ Change & CTE $\left(\alpha_{2}\right), \mu \mathrm{m} / \mathrm{m} \cdot{ }^{\circ} \mathrm{C}$ & $\left(\alpha_{2}-\alpha_{1}\right) \mu \mathrm{m} / \mathrm{m} \cdot{ }^{\circ} \mathrm{C}$ \\
\hline Neat & $58.40 \pm 2.91$ & - & $184.60 \pm 3.45$ & - \\
\hline 0.1 wt.\% GNP & $60.28 \pm 2.14$ & 3.22 & $172.80 \pm 0.63$ & -6.4 \\
\hline 0.2 wt.\% GNP & $63.14 \pm 0.10$ & 8.17 & $172.73 \pm 0.91$ & -6.43 \\
\hline 2 wt.\% MMT & $65.73 \pm 1.09$ & 12.55 & $172.15 \pm 0.12$ & -6.74 \\
\hline 3 wt.\% MMT & $66.06 \pm 2.36$ & 13.17 & $168.43 \pm 0.92$ & -8.78 \\
\hline Binary & $58.91 \pm 3.32$ & 0.87 & $165.87 \pm 2.87$ & -10.14 \\
\hline
\end{tabular}

binary system resulted in an increased crosslink density with lack of room for dimensional changes in $\alpha_{1}$ values [10].

Post transition CTE values of all nanocomposites showed lower values of $\alpha_{2}$, compared to neat, with binary nanocomposites showing the least values. This was attributed to formation of linkages and crosslinking between the nanofillers and epoxy molecules at elevated temperatures, resulting in restrictive chain mobility. Changes between the two CTE $(\alpha)$ values are indicative of dimensional stability of the composite material at elevated temperatures. In the current samples with 3 wt \% MMT loading showed the least changes, while 0.1 wt \% GNP recorded the highest, with binary between the two.Thus, with increasing temperature control samples transformed from glassy to rubbery structures losing its dimensional stability, while nanocomposites became thermally more stable [13]. The results also showed that $\alpha_{2}$ values decreased in all nanocomposites compared to neat system, with binary showing the least $\alpha_{2}$ values among all samples. This may be attributed to increased crystallinity or crosslinked density in post transition systems compared to neat, which may have reduced presence of free volume in the system, giving rise to lowered steric hindrance [10].

Representative TMA thermographs of samples conditioned to 240 days of seawater exposure is presented in (Figure 8b) and average data presented in (Table 3). Analysis of the thermographs showed unique characteristic of rapid expansion of all nanocomposite samples 
Table 3: Comparison of CTE values of Conditioned Neat and Nanocomposites Samples.

\begin{tabular}{|c|c|c|c|}
\hline Sample & CTE $\left(\alpha_{1}\right), \mu \mathrm{m} / \mathrm{m} \cdot{ }^{\circ} \mathrm{C}$ & $\%$ Change & $\mathrm{CTE}\left(\alpha_{2}\right), \mu \mathrm{m} / \mathrm{m} \cdot{ }^{\circ} \mathrm{C}$ \\
\hline Neat & $99.98 \pm 0.67$ & - & $173.90 \pm 0.41$ \\
\hline 0.1 wt.\% GNP & $96.30 \pm 3.51$ & -3.68 & $185.33 \pm 5.05$ \\
\hline 0.2 wt.\% GNP & $102.17 \pm 2.65$ & 2.19 & $188.43 \pm 0.11$ \\
\hline 2 wt.\% MMT & $92.01 \pm 1.75$ & -7.97 & $181.07 \pm 2.02$ \\
\hline 3 wt.\% MMT & $113.77 \pm 12.53$ & 13.79 & $181.20 \pm 0.92$ \\
\hline Binary & $80.54 \pm 9.38$ & -19.44 & 4.12 \\
\hline
\end{tabular}

Table 4: Summary of TGA data for unconditioned samples.

\begin{tabular}{|c|c|c|c|c|c|c|}
\hline Sample & Onset of Decomposition $\left({ }^{\circ} \mathrm{C}\right)$ & $\%$ Change & Decomposition Temperature $\left({ }^{\circ} \mathrm{C}\right)$ & $\%$ Change & $\begin{array}{c}\text { Residue, } \\
\%\end{array}$ & $\%$ Change \\
\hline Neat & $329 \pm 0.77$ & - & $337 \pm 0.13$ & - & $12.16 \pm 0.04$ & - \\
\hline 0.1 wt. \% GNP & $284 \pm 0.60$ & -13.71 & $291 \pm 0.82$ & -13.67 & $11.69 \pm 0.06$ & -3.87 \\
\hline 0.2 wt. \% GNP & $282 \pm 0.55$ & -14.43 & $291 \pm 1.07$ & -13.78 & $11.61 \pm 0.01$ & -4.52 \\
\hline 2 wt. \% MMT & $327 \pm 1.17$ & -0.56 & $336 \pm 0.88$ & -0.31 & $13.49 \pm 0.04$ & 10.94 \\
\hline 3 wt. \% MMT & $323 \pm 0.49$ & -1.77 & $337 \pm 0.58$ & 0.01 & $13.56 \pm 0.11$ & 11.51 \\
\hline Binary & $301 \pm 0.58$ & -8.51 & $309 \pm 0.96$ & -8.18 & $13.34 \pm 0.07$ & 9.70 \\
\hline
\end{tabular}

Table 5: Summary of TGA data for conditioned samples.

\begin{tabular}{|c|c|c|c|c|c|c|}
\hline Sample & Onset of Decomposition, ${ }^{\circ} \mathrm{C}$ & $\%$ Change & Decomposition Temperature $\left({ }^{\circ} \mathrm{C}\right)$ & $\%$ Change & Residue, \% & $\%$ Change \\
\hline Neat & $285.5 \pm 0.25$ & - & $296.2 \pm 0.49$ & - & $9.86 \pm 0.04$ & - \\
\hline $0.1 w t . \%$ GNP & $278.9 \pm 1.73$ & -2.3 & $298.3 \pm 0.76$ & 0.69 & $10.09 \pm 0.10$ & 2.33 \\
\hline 0.2 wt. $\%$ GNP & $275.1 \pm 2.02$ & -3.66 & $297.8 \pm 0.50$ & 0.56 & $10.61 \pm 0.01$ & 7.61 \\
\hline 2 wt. \% MMT & $281.4 \pm 0.30$ & -1.46 & $295.4 \pm 0.90$ & -0.27 & $11.11 \pm 0.11$ & 11.66 \\
\hline 3 wt. \% MMT & $280.9 \pm 1.02$ & -1.61 & $296.4 \pm 0.46$ & 0.06 & $11.63 \pm 0.11$ & 17.95 \\
\hline Binary & $277.5 \pm 0.89$ & -2.79 & $287.2 \pm 0.43$ & -3.04 & $11.51 \pm 0.12$ & 16.73 \\
\hline
\end{tabular}

just before glass transition region compared to neat. This behavior was attributed to swelling and plasticization of the matrix caused by prolonged exposure of samples to seawater leading to changes in their microstructure. Characteristic bridging effects may have influenced dimensional expansion causing polymer macromolecules to expand at elevated temperatures along the length of these nanoparticles. This results in plastic deformation and breaking of long polymer chains into smaller macromolecular chain collectively increasing the overall changes in the system, and lowering the glass transition temperature [22]. No significant changes were observed in $\alpha_{2}$ values of all samples after glass transition. Thus, exposure to seawater and its effect on composite samples become independent of the system. Maximum dimensional changes in conditioned samples occurred in $0.2 \mathrm{wt} \%$ GNP and 3 wt \% MMT loadings, due to moisture induced stresses as these samples absorbed the most moisture during conditioning.

\section{Thermal stability}

Representative TGA curves of weight loss as function of temperature for unconditioned and samples conditioned for 240 days of seawater exposure are shown in (Figures 9a,b). Onset of decomposition of SC 780 was significantly impacted by the addition of different nanoparticles, dictated by their inherent properties and interactions with polymer molecules [13]. These properties include high thermal conductivities and thermal stability influencing various properties of polymer composites [1-3]. There was approximately $14 \%$ decrease in onset temperatures and temperatures at which maximum decomposition occurred in all GNP and binary modified samples respectively. This decrease was attributed to extremely high thermal conductivity of GNP nanoparticles, which transmitted the heat through the resin causing the polymer molecules to degrade at a faster rate [23].

On the other hand, MMT nanocomposites performed better than all the other nanocomposite samples due to its inherent fire retardancy property, giving rise to enhanced thermal stability of the system $[11,24]$. Thermal decomposition behavior of MMT modified samples was identical to that of neat samples, despite enhanced thermal properties of MMT. Residue obtained at the end of the TGA scan showed a decrease by nearly 3.9 and $4.5 \%$ for 0.1 and $0.2 \mathrm{wt} \%$ GNP nanocomposites respectively. On the other hand, there was an increase in residue for 2 and $3 \mathrm{wt} \%$ MMT loaded samples by 10.94 and $11.50 \%$ respectively, due to comparatively higher loading. A synergy between the binary nanoparticles was observed based on the individual performance of $3 \mathrm{wt} \% \mathrm{MMT}$ and $0.1 \mathrm{wt} \%$ of GNP seen from (Table 4). GNP nanoparticles seemed to acceleratethe decomposition process, while MMT nanoparticles tend to have the opposite effect. This resulted in enhanced thermal stability of binary nanocomposites with respect to neat and other individual nanoparticle systems at higher temperatures. It can also be observed from (Figure 9), that the decomposition mechanism of binary system was indifferent from that of individual nanoparticle-modified systems and neat system. Samples with MMT showed insignificant decomposition parameters 
to that of neat, while that of GNP samples reported lower values. To compensate for this effect, addition of MMT nanoparticles proved to useful in achieving optimized thermal properties in binary epoxy composite compared to GNP samples.

Summary of thermal stability studies on conditioned samples are presented in (Table 5), showing the impact of seawater on thermal properties. Overall, thermal stability of conditioned samples decreased compared to their respective unconditioned counterparts, largely due to microstructural changes caused by the absorbed seawater [13] Onset and temperature at which maximum rate of decomposition occurred in each sample decreased in all conditioned samples compared to neat and their respective unconditioned counterpart. An initial weight lost observed around $100^{\circ} \mathrm{C}$ was attributed to evaporation of entrapped moisture within the composite. Onset of decomposition taken at $5 \%$ of initial weight loss showed slightly lower values for all nanocomposites compared to neat system. Table 5 shows 8 that binary nanocomposites were relatively less thermally stable in case of conditioned samples. Comparison of key thermal decomposition parameters between unconditioned and conditioned samples, showed that temperature at which maximum decomposition occurred decreased for all samples expect GNP loaded samples.

\section{Conclusion}

Influence of combined MMT and GNP on thermo-mechanical and thermal properties of epoxy SC780 composites along with the impact of seawater conditioning on these properties was studied. Results from the study showed sufficient interaction between MMT/ GNP in a binary nanocomposite. The synergy between binary nanoparticles resulted in relatively lower absorption of seawater compared to samples with individual nanoparticle infused system and neat. Binary nanoparticles also showed better enhancement in storage modulus and dimensional stability at elevated temperatures compared to other nanocomposites and neat samples. It can be inferred from the results that binary nanocomposites display enhanced crosslinking density compared to neat and other nanocomposites. TGA studies showed poor or insignificant changes in onset and decomposition temperatures, and an increase in char formation in all nanocomposites samples compared to unmodified counterpart.

\section{Acknowledgment}

The authors would like to acknowledge financial support from Army Research Office (ARO) through Grant number W911NF-15-1-0451 for funding this research.

\section{References}

1. Atif R, Shyha I, Inam F. Mechanical, thermal, and electrical properties of graphene-epoxy nanocomposites-A review. Polymers. 2016; 8: 281.

2. Zabihi O, Ahmadi M, Nikafshar S, Preyeswary KC, Naebe M. A technical review on epoxy-clay nanocomposites: Structure, properties, and their applications in fiber reinforced composites. Composites Part B: Engineering. 2017.

3. Kuilla T, Bhadra S, Yao D, Kim NH, Bose S, Lee JH. Recent advances in graphene based polymer composites. Progress in polymer science. 2010; 35: $1350-1375$

4. Tcherbi-Narteh A, Hosur M, Jeelani S. Influence of nanoclay on the durability of woven carbon/epoxy composites subjected to ultraviolet radiation. Mechanics of Advanced Materials and Structures. 2014; 21: 222-236.

5. Zainuddin S, Hosur MV, Zhou Y, Kumar A, Jeelani S. Durability study of neat/nanophased GFRP composites subjected to different environmental conditioning. Materials Science and Engineering: A. 2010; 25: 527: 30913099.

6. Ci L, Song L, Jin C, Jariwala D, Wu D, Li Y, et al. Atomic layers of hybridized boron nitride and graphene domains. Nature materials. 2010; 9: 430.

7. Lau KT, Gu C, Hui D. A critical review on nanotube and nanotube/nanoclay related polymer composite materials. Composites Part B: Engineering. 2006; 37: 425-436.

8. Lee GW, Park M, Kim J, Lee JI, Yoon HG. Enhanced thermal conductivity of polymer composites filled with hybrid filler. Composites Part A: Applied science and manufacturing. 2006; 37: 727-734.

9. Chan ML, Lau KT, Wong TT, Cardona F. Interfacial bonding characteristic of nanoclay/polymer composites. Applied surface science. 2011; 258: 860-864.

10. Putz KW, Palmeri MJ, Cohn RB, Andrews R, Brinson LC. Effect of Cross-Link Density on Interphase Creation in Polymer Nanocomposites. Macromolecules. 2008; 41: 6752-6756.

11. Carrasco F, Pagès $P$. Thermal degradation and stability of epoxy nanocomposites: influence of montmorillonite content and cure temperature. Polymer Degradation and Stability. 2008; 93: 1000-1007.

12. Tcherbi-Narteh A, Hosur M, Triggs E, Owuor P, Jelaani S. Viscoelastic and thermal properties of full and partially cured DGEBA epoxy resin composites modified with montmorillonite nanoclay exposed to UV radiation. Polymer Degradation and Stability. 2014; 101: 81-91.

13. Terrones M, Martín O, González M, Pozuelo J, Serrano B, Cabanelas JC, et al. Interphases in Graphene Polymer-based Nanocomposites: Achievements and challenges. Advanced Materials. 2011; 23: 5302-5310.

14. Tcherbi-Narteh A, Hosur M, Jeelani S. Effects of Different Montmorillonite Nanoclay Loading on Cure Behavior and Properties of Diglycidyl Ether of Bisphenol A Epoxy. Journal of Nanomaterials. 2016; 2016: 1-12.

15. Weitsman YJ. Effects of Fluids on Mechanical Properties and Performance. In Fluid Effects in Polymers and Polymeric Composites Springer Boston MA. 2012.

16. Faguaga E, Pérez CJ, Villarreal N, Rodriguez ES, Alvarez V. Effect of water absorption on the dynamic mechanical properties of composites used for windmill blades. Materials \& Design (1980-2015). 2012; 36: 609-616.

17. Abanilla MA, Li Y, Karbhari VM. Durability characterization of wet layup graphite/epoxy composites used in external strengthening. Composites Part B: Engineering. 2005; 37: 200-212.

18. Rao RM, Balasubramanian N, Chanda M. Factors affecting moisture absorption in polymer composites part I: influence of internal factors. Journal of reinforced plastics and composites. 1984; 3: 232-245.

19. Alamri H, Low IM. Effect of water absorption on the mechanical properties of nano-filler reinforced epoxy nanocomposites. Materials \& Design. 2012;42: 214-22.

20. Chan ML, Lau KT, Wong TT, Ho MP, Hui D. Mechanism of reinforcement in a nanoclay/polymer composite. Composites Part B: Engineering. 2011; 42: 1708-12.

21. Zuo L, Fan W, Zhang Y, Zhang L, Gao W, Huang Y, et al. Graphene/ montmorillonite hybrid synergistically reinforced polyimide composite aerogels with enhanced flame-retardant performance. Composites Science and Technology. 2017; 139: 57-63.

22. Fu SY, Feng XQ, Lauke B, Mai YW. Effects of particle size, particle/ matrix interface adhesion and particle loading on mechanical properties of particulate-polymer composites. Composites Part B: Engineering. 2008; 39: 933-961.

23. Ganguli S, Roy AK, Anderson DP. Improved thermal conductivity for chemically functionalized exfoliated graphite/epoxy composites. Carbon. 2008; 46: 806-817.

24. Tcherbi-Narteh A, Hosur M, Triggs E, Jeelani S. Thermal stability and degradation of diglycidyl ether of bisphenol A epoxy modified with different nanoclays exposed to UV radiation. Polymer degradation and stability. 2013; 98: 759-770. 